\title{
A importância da contra-imunoeletroforese na detecção de antígenos nucleares extraiveis para 0 diagnóstico de doenças reumáticas sistêmicas
}

\author{
The importance of counterimmunoelectrophoresis in the detection of extractable nuclear antigens \\ for the diagnosis of systemic rheumatic diseases
}

Rita de Cassia Siqueira Bruder¹ ; Izaíra Máximo de Carvalho Prudente²; Maria Isabel Corrêa da Silva²; Julio Defaveri ${ }^{3}$

\begin{abstract}
unitermos
Auto-anticorpos

Testes sorológicos

Antigenos nucleares

extraiveis

Contra-imunoeletroforese

\section{resumo}

Os antígenos nucleares extraíveis (ENAs) são encontrados no soro da maioria dos pacientes com doença reumática sistêmica. Os principais ENAs estudados são SS-A/Ro, SS-B/La, RNP, Sm, Scl-70 e Jo-1. Objetivou-se neste trabalho: a) padronizar a técnica de contra-imunoeletroforese (CIE) para a detecção de ENAs; b) padronizar o substrato antigênico (ENAs) para a CIE a partir de baço de cão; c) comparar os resultados da CIE com as técnicas de imunofluorescência indireta (IFI) e Elisa para esses antígenos. Para tal foram estudados 40 soros de pacientes com doença reumática sistêmica confirmada por exames clínico e laboratorial (sorológico e biópsia). Como controle negativo foram utilizados dez soros de doadores de sangue normais, e, como controles positivos, seis soros-padrão anti-Ro, anti-La, anti-RNP, anti-Sm, anti-Scl-70, anti-Jo-1, para caracterizar os antígenos presentes no extrato de baço. Neste último foram detectados vários ENAs, exceto RNP e Scl-70. A técnica de CIE apresentou boas sensibilidade (70\%) e especificidade (100\%) em relação às outras técnicas (IFI e Elisa). A titulação dos soros pela CIE revelou positividade até diluições de 1:16 em 32,5\% dos casos. Concluímos que a CIE e os antígenos extraídos de baço de cão podem ser utilizados na rotina laboratorial para triagem destes ENAs, com a vantagem, em relação à IFI, de poderem ser titulados.
\end{abstract}

Extractable nuclear antigens (ENAs) are detected in the sera of the majority of patients with rheumatic systemic disease. The main ENAs studied are SS-A/Ro, SS-B/La, RNP, Sm, SCl-70 and Jo-1. The aim of this work was: a) to standardize the counterimmunoelectrophoresis technique (CIE) to detect ENAs; $b$ ) to standardize the extration of ENAs from dog spleen as a substract for CIE test; c) to compare the results obtained by CIE with those of indirect immunofluorescence (IFI) and Elisa for these antigens. Forty sera from individuals with rheumatic systemic disease confirmed by clinical and serological tests and by skin and/or kidney biopsies were tested. Ten normal sera from blood donors were used as negative control, and as positive control to check for ENAs in the spleen extract, six positive sera for anti-Ro, anti-La, anti-RNP, anti-Sm, anti-Scl-70, anti-Jo-1 were tested. The spleen extract contained many of the ENAs antigens, except RNP and SCl-70. CIE showed good sensitivy (70\%) and specificity (100\%) in relation to IFI and Elisa. Also, by CIE the positive sera could be diluted up to 16 dilution (32.5\%). We concluded that $C I E$, together with antigens extracted from dog spleen, could be used in the laboratorial routine to detect ENAs, and compared to IFI, with the advantage that sera can be titulated. key words

Autoantibodies

Serologic tests

Extractable nuclear

antigens

Counterimmunoelectrohoresis

1. Bióloga.

2. Pesquisadora técnica.

3. Livre-docente.

Trabalho realizado no Laboratório de Imunopatologia do Dep

de Estadual Paulista, campus Botucatu (Unesp/Botucatu).

Dissertação apresentada ao curso de pós-graduação 


\section{Introdução}

As doenças auto-imunes se caracterizam pela autoagressão determinada pelo sistema imune contra antígenos constitutivos do próprio indivíduo ${ }^{(9)}$. Tanto a imunidade humoral quanto a celular, isoladas ou associadas, estão envolvidas na patogênese das doenças auto-imunes ${ }^{(25)}$. Estes mecanismos são bem conhecidos em uma variedade de doenças humanas, e muito estudados em excelentes modelos animais ${ }^{(8)}$. Dependendo do antígeno escolhido, a auto-agressão pode ocorrer de forma localizada em um órgão (órgão-específica), como nas tireoidites, ou ser sistêmica (órgão-inespecífica), como na doença lúpica ${ }^{(25)}$.

Os anticorpos circulantes observados nas doenças autoimunes se caracterizam por apresentar especificidade para diversos constituintes do citoplasma e/ou do núcleo das células ${ }^{(15)}$. Vários antígenos de localização nuclear e citoplasmática foram descritos nas doenças auto-imunes ${ }^{(18)}$. Os mais freqüentes são os antígenos nucleares, os quais, devido ao processo usado para purificá-los, são denominados antígenos nucleares extraíveis, mais comumente representados pela sigla ENA (extractable nuclear antigens) $)^{(19)}$.

Os principais ENAs estudados são: SS-A/Ro (52 e $60 \mathrm{KDa})^{(16)}$, presente em pacientes com lúpus eritematoso sistêmico (LES: 30\%-50\%) e síndrome de Sjögren (SS: $50 \%-90 \%)$, SS-B/La (48 e 50KDa) $)^{(5)}$, em LES (15\%) e SS (35\%-85\%), RNP (proteínas de 22, 33 e 70KDa), presente em LES (30\%), doença mista do tecido conjuntivo (DMTC: $95 \%$ ) e esclerodermia sistêmica progressiva (ESP: 10\%), Sm (proteínas de 13, 16, 28 e $29 \mathrm{KDa})^{(27)}$, encontrado em $30 \%$ dos pacientes com LES, Scl-70 (proteínas de 70 e $100 \mathrm{KDa})^{(1,7)}$, presente em $70 \%$ de esclerodermia difusa, e Jo-1 (proteína de 50KDa) ${ }^{(19,1)}$, presente em 25\% dos casos de dermatomiosite e polimiosite.

Um dos pontos importantes em todos os testes de detecção de anticorpos é a utilização de antígenos adequados. Vários substratos têm sido utilizados nos diferentes testes como fonte de antígenos para detecção dos auto-anticorpos, porém os ENAs são geralmente obtidos de baço(4) ou timo ${ }^{(13)}$. Atualmente tem-se utilizado como substrato células humanas cultivadas, como as células HEp-2, obtidas do carcinoma de laringe humana ${ }^{(12)}$. Estas células têm-se revelado um ótimo substrato, pois intensificam a detecção de antígenos nucleares relacionados ao ciclo celular humano. Além disso, linhagens de células humanas que expressam antígenos nucleares em baixa concentração ${ }^{(22)}$ têm sido recombinadas com seqüências de DNA capazes de expressar estes antígenos, aumentando, assim, o poder do teste ${ }^{(3)}$.
Vários métodos têm sido descritos para a detecção de auto-anticorpos, citando-se imunofluorescência indireta (IFI), imunocitoquímica, difusão dupla, dot blot, Western blot, imunoprecipitação, ensaio imunoenzimático Elisa e contra-imunoeletroforese (CIE). Estudos comparando a especificidade e a sensibilidade de diferentes métodos para a detecção de anticorpos ENA têm mostrado que não há consenso sobre o melhor método ${ }^{(6)}$. A CIE, também conhecida como eletrocinerese ou imunoeletromosforese, tem sido aplicada para imunodiagnóstico de várias desordens. Caracteriza-se pelas altas sensibilidade e especificidade. Obter testes mais sensíveis e específicos e de menor custo para o diagnóstico das doenças auto-imunes é objetivo ainda a ser alcançado, sendo constantes as descrições na literatura de novos métodos buscando satisfazer estes objetivos.

Os objetivos do presente trabalho foram: a) padronizar a técnica de contra-imunoeletroforese para a detecção de ENAs; b) padronizar o substrato antigênico para a CIE a partir de baço de cão; c) comparar os resultados da CIE com as técnicas de IFI e Elisa para esses antígenos.

\section{Material e métodos}

\section{Casuística}

Foram estudados 40 soros de pacientes com diagnóstico confirmado de doença reumática, sendo assim distribuídos: LES = 29 casos (72\%); lúpus eritematoso discóide (LED) = quatro casos (10\%); síndrome de Sjögren $(\mathrm{SS})=$ quatro casos $(10 \%)$; e esclerodernia $(\mathrm{ESCL})=$ três casos (7,5\%). Quanto ao sexo, 34 eram do sexo feminino e seis do sexo masculino. A idade variou de 8 a 80 anos, com média de 27 anos. Como controle foram utilizados dez soros de indivíduos normais (quatro do sexo feminino e seis do sexo masculino), provenientes de doadores de sangue do hemocentro da Faculdade de Medicina de Botucatu da Universidade Estadual Paulista (FMB/Unesp). Todos os soros (pacientes e controles) foram submetidos aos seguintes testes: IFI-FAN, IFI-DNA, ENA (Sm e RNP), Elisa-Ro, Elisa-La e CIE.

\section{Métodos}

Os testes IFI-FAN (Immco Diagnostics-963 Kenmore Avenue, Buffalo, NY), IFI-DNA (Immco Diagnostics963 Kenmore Avenue, Buffalo, NY), ENA (Sm e RNP) (Hemagen Diagnostics, Inc. 34-40 Bear Hill Road, Waltham, Massachusetts), Elisa-Ro (Hemagen Diagnostics, Inc. 34-40 Bear Hill Road, Waltham, Massachusetts) e Elisa-La (Hemagen) foram realizados utilizando-se kits 
específicos para cada teste, seguindo-se as especificações do fabricante.

\section{Padronização dos antígenos}

Os antígenos para execução da CIE foram obtidos de baços de cães sadios. Os órgãos foram retirados imediatamente após indução anestésica com pentobarbital sódico (30 $\mathrm{mg} / \mathrm{kg}$ peso), pesados (peso médio $60 \mathrm{~g}$ ) e macerados em $120 \mathrm{ml}$ de PBS pH 7,2 gelado. A suspensão foi centrifugada em número de vezes suficiente para se obter um sobrenadante límpido. Os antígenos foram eluídos em cromatografia de troca iônica, obtendo-se picos de proteínas que foram dialisados e liofilizados. A dosagem protéica foi realizada pelo método de Lowry et al. ${ }^{(17)}$, sendo a concentração protéica final $1,7 \mathrm{mg} / \mathrm{ml}$.

\section{Contra-imunoeletroforese}

Para consecução da CIE, lâminas de vidro $(50 \times 75 \mathrm{~mm})$ foram recobertas com agarose em tampão barbital 0,5M, e, com auxílio de gabarito, foram realizados poços de $20 \mu \mathrm{l}$ dispostos verticalmente em quatro colunas com cinco poços. Os soros dos pacientes ou controles foram introduzidos no lado catódico da lâmina, a qual foi submetida a eletroforese por 30 minutos em câmara contendo solução barbital diluída 1:5 sob uma corrente de intensidade constante de $12 \mathrm{~mA}$. Logo após, a lâmina foi retirada - os orifícios do lado anódico foram preenchidos com $20 \mathrm{ml}$ do antígeno liofilizado (diluição a $20 \%$ em PBS pH 7,2) - e novamente submetida a eletroforese com a mesma intensidade por 15 min. Posteriormente, a lâmina foi colocada em câmara úmida por uma noite e realizada a leitura por dois observadores independentes. A positividade foi revelada por linhas de precipitação.

\section{Teste do extrato de baço contra soros-controle positivos}

Como o extrato de baço contivesse uma mistura dos diferentes antígenos estudados nas doenças reumáticas, o mesmo foi testado pela CIE contra soros específicos para Ro, La, Ro-La, RNP, Sm, RNP-Sm, Scl-70, Jo-1, gentilmente cedidos pelo prof. dr. Paulo Guilherme Leser (Laboratório Fleury-SP).

\section{Resultados}

- Teste do soro-controle negativo - Não foram detectados auto-anticorpos nestes soros.

- Teste do extrato de baço com soro-controle positivo-O teste do extrato de baço contra os soros-controle positivos apresentou positividade para anti-Ro, anti-La, anti-Ro/La, antiSm, anti-Jo-1 e negatividade para anti-RNP e anti-Scl-70.

- Resultados dos testes - Na grande maioria dos casos a posivitividade foi evidenciada por apenas uma linha de precipitação; apenas dois testes apresentaram duas linhas de precipitação. A Tabela 1 mostra a freqüência de positividade dos testes realizados em cada doença. A maior positividade foi observada com a IFI-FAN (88\% - 35 testes), e a menor, com o teste anti-DNA ( $20 \%-8$ testes). A CIE apresentou a segunda maior freqüência, com $70 \%$ dos casos (28 testes) assim discriminados: ESCL - 100\% positivos; LES - 66\% positivos; LED e SS - $75 \%$ positivos.

A CIE apresentou sensibilidade de $70 \%$ e especificidade de $100 \%$. Para os testes Elisa-Ro e La a sensibilidade foi de $42,5 \%$ e $35 \%$ respectivamente, e a especificidade foi $100 \%$ para ambos os testes.

A Tabela 2 mostra a titulação dos soros pela CIE nas diferentes doenças. Dos 40 soros, 12 foram negativos e 13 tiveram

\section{Tabela 1 Frequêência de resultados positivos por doença e sensibilidade dos diferentes testes}

\begin{tabular}{|c|c|c|c|c|c|c|}
\hline Testes & $\begin{array}{c}\text { LES } \\
(n=29)\end{array}$ & $\begin{array}{l}\text { LED } \\
(n=4)\end{array}$ & $\begin{array}{c}\text { Doenças } \\
\text { SS } \\
(n=4)\end{array}$ & $\begin{array}{l}\text { ESCL } \\
(n=3)\end{array}$ & $\begin{array}{c}\text { Total } \\
(n=40)\end{array}$ & $\begin{array}{c}\text { Sensibilidade } \\
(\%)\end{array}$ \\
\hline CIE & 19 & 3 & 3 & 3 & 28 & 70 \\
\hline Elisa-Ro & 13 & 2 & 1 & 1 & 17 & 43 \\
\hline Elisa-La & 10 & 2 & 1 & 1 & 14 & 35 \\
\hline IFI-FAN & 26 & 3 & 3 & 3 & 35 & 88 \\
\hline IFI anti-DNA & 7 & 1 & - & - & 8 & 20 \\
\hline Elisa-RNP & 16 & 1 & 1 & - & 18 & 45 \\
\hline Elisa-Sm & 14 & 1 & 1 & - & 16 & 40 \\
\hline
\end{tabular}


Tabela 2 Titulação dos soros pela CIE nas diferentes doenças

\begin{tabular}{lcccccc}
\hline & \multicolumn{5}{c}{ Titulação dos soros } \\
Doenças & Negativo & Puro & 2 & 4 & 8 & 16 \\
ESCL & - & 2 & 1 & - & - & - \\
LES & 10 & 6 & - & - & 4 & 9 \\
LED & 1 & 1 & - & - & - & 2 \\
SS & 1 & - & 1 & - & - & 2 \\
Total & $12(30 \%)$ & $9(22,5 \%)$ & $2(5 \%)$ & - & $4(10 \%)$ & $13(32,5 \%)$ \\
\hline
\end{tabular}

ESCL: esclerodermia; LES: lúpus eritematoso sistêmico; LED: lúpus eritematoso discóide; SS: síndrome de Sjögren.

titulação 16; destes, nove soros eram de pacientes com LES, dois de pacientes com LED e dois de pacientes com SS.

\section{Discussão}

Embora os auto-anticorpos presentes nas doenças reumáticas sejam rotineiramente denominados fatores antinúcleo (FAN), sabe-se que são dirigidos não somente contra antígenos nucleares, mas também contra estruturas citoplasmáticas. A pesquisa destes auto-anticorpos não está mais restrita à IFI, pois essa técnica pode não detectar alguns anticorpos, levando a resultado falso negativo(2, 23). A IFI é um importante teste de triagem, e teve sua sensibilidade aumentada quando se passou a utilizar como substrato as células de carcinoma de laringe humana (HEp-2) em substituição aos imprints e às secções de congelação de fígado e rim de roedores ${ }^{(10,24)}$. Este aumento da sensibilidade deve-se ao fato de as células HEp-2, por estarem em constante divisão, expressarem antígenos inexistentes nas células hepáticas e renais dos roedores.

Os anticorpos anti-DNA são marcadores de LES e têm sido detectados através da IFI utilizando-se como substrato o hemoflagelado Crithidia luciliae. Entretanto, com este substrato a positividade é muito baixa, ao redor de $20 \%{ }^{(25)}$. Esta baixa positividade deve-se ao fato de a C. luciliae muitas vezes aparecer toda corada, e não apenas o cinetoplasto, como desejado, tornando o resultado muito subjetivo. Este fato, aliado à grande dificuldade em se cultivar este flagelado, levou a maioria dos laboratórios a substituir este teste com grande vantagem pelo Elisa ${ }^{(11,14,26,29)}$.

Ao se considerar um teste para detectar anticorpos, são relevantes a técnica propriamente dita e a qualidade do substrato (antígeno) utilizado (20, 21). No presente trabalho utilizamos a CIE, por ser método sensivel, e, como antígeno, o extrato de baço, por conter marcadores importantes das doenças reumáticas. O baço de cão foi escolhido considerando-se dados de literatura, mostrando ser boa fonte destes antígenos ${ }^{(22,28)}$, e, também, pela facilidade em obtê-lo no laboratório de cirurgia experimental de nosso campus. A extração de antígenos teciduais é tarefa complexa, mormente se considerarmos órgãos como o fígado, timo e baço, constituídos por vários tecidos. Nestes casos, o extrato fornece inúmeros antígenos, provenientes dos inúmeros constituintes celulares e subcelulares. Além disso, o procedimento utilizado para sua extração pode alterar as propriedades antigênicas, dificultando ainda mais sua detecção. No presente trabalho, a presença e a antigenicidade dos ENAs foram avaliadas utilizando-se soros e antígenos padrões contra os antígenos Ro, La, Sm, RNP,Scl-70, Jo1, revelando negatividade apenas para RNP, Scl-70.

O teste de CIE mostrou-se específico e sensível para detecção de auto-anticorpos. A sensibilidade do teste foi de $70 \%$, e a especificidade, de $100 \%$. A CIE apresentou sensibilidade semelhante à IFI ( $70 \%$ contra $88 \%$, respectivamente), que também é um teste de triagem. Entretanto, ao possibilitar a quantificação dos auto-anticorpos, a CIE poderia ser utilizada em trabalhos futuros para estudar possíveis correlações entre os níveis de anticorpos e a gravidade da doença.

Uma limitação da CIE observada no presente trabalho foi a caracterização específica dos ENAs. Na grande maioria dos testes foi observada apenas uma linha de precipitação, indicando a presença de anticorpos contra um dos antígenos presentes no extrato de baço. Seriam importantes a caracterização e a separação desses antígenos, pois possibilitaria detectar cada um dos anticorpos e, assim, poder correlacioná-los individualmente com cada doença auto-imune.

Um resultado inesperado ocorreu, já que, dos 40 soros estudados de paciente reumáticos, 12 foram negativos pela CIE. Teoricamente, todos deveriam ser positivos. Não temos uma explicação definitiva para este resultado. Isto poderia ser explicado em parte pela ausência ou pela baixa concentração de alguns antígenos no extrato de baço (os 
soros-padrão não detectaram os antígenos RNP e Scl-70) e/ou pela baixa concentração de determinados anticorpos no soro desses casos negativos.

Em conclusão, embora a IFI seja usada como teste rotineiro para triagem de auto-anticorpos, a CIE, por ser teste de grande sensibilidade, pode também ser introduzida para a triagem sorológica dos ENAs, com a vantagem de permitir a titulação dos auto-anticorpos.

\section{Agradecimentos}

Agradecemos ao prof. dr. Paulo Guilherme Leser, do Laboratório Fleury, pela doação dos soros controle-positivos; à Hemagen Diagnostics Inc., pela doação dos kits anti-Ro e anti-La utilizados neste trabalho; e à Coordenação de Aperfeiçoamento de Pessoal de Nível Superior (CAPES), pela bolsa de mestrado oferecida ao curso de pós-graduação em Patologia.

\section{Referências}

I.BERNSTEIN, R. M. et al. Anti-Jo- I antibody: a marker for myositis with interstitial lung disease. BrMed J, v. 189, p. 151-2, 1984.

2. BLOMBERG, S. et al. Anti-SSA/Ro antibody determination by enzyme-linked immunosorbent assay as a supplement to standard immunofluorescence in antibody screening. Scand I Immunol, v. 5I, p. 612-7, 2000.

3. BOSSUYT, $X$. et al. Screening for autoantibodies to SS-A/Ro by indirect immunofluorescence using HEp-2000 cells. Ann Clin Biochem, v. 37, p. 216-9, 2000.

4. BOZIC, B. et al. Sera from patients with rheumatic diseases recognize different epitope regions on the $52 \mathrm{KDa}$ Ro/SS-A protein. Clin Exp Immunol, v. 94, p. 227-37, 1995

5. CHAN, E. K. L.;AN, E. M. Epitopes, structural domains and asymmetry of amino acid residues in SS-B/La nuclear protein. I Immunol, v. 136, p. 3744-9, 1986

6. COOK, L. New methods for detection of anti-nuclear antibodies Clin Immunol Immunophatol, v. 88, p. 21 I-20, 1998.

7. DOUVAS, A. S. et al. Identification of a nuclear protein ( $\mathrm{Cl}-70)$ as unique target of human antinuclar antibodies in scleroderma. J Biol Chem, v. 254, p. I05। 4-22, 1979.

8. ELKON, K. B.; BONFA, E.; LLOVET, R. et al. Association between anti-Sm and anti-ribosomal $P$ protein autoantibodies in human systemic lupus erythematosus and MRL/lpr mice.J Immunol, v. |43, p. 1549-54, 1989

9. FLAVELL, R. A., HAFLER, D. A. What is the turning point? Curr Opin Immunol, v. II, p. 635-7, 1999

10. HOLBOROW, E.J. et al.A serum factor in lupus erythematosus with affinity for tissue nuclei. BrMed J, v. 2, p. 732, 1957.

I I.KAPOGIANNIS, B. et al. Differences in clinical sensitivity of Elisa tests for autoantibodies with human and bovine extractable nuclear antigens. Lupus, v. 9, p. 343-52, 2000.

12.KERN, P. et al. Measurement of antinuclear antibodies: assessment of different test systems. Clin Diag Lab Immun, v. 7, p. 72-8, 2000.

13. KOZEN, F. et al. A comparison of the sensitivities and specificities of different substrates for the fluorescent antinuclear antibody test. Am J Clin Pathol, v. 74, p. 785-90, 1980.

14. KRAUTHAMER, A. et al. Enzyme-linked immunosorbent assay for semi-quantitation of anti-Ro/SS-A antibodies in autoimmune rheumatic diseases. Rev Bras Rheumatol, v. 35, n. 6. p. 315-20, 1995.

15. KURIEN, B. T. et al. Association of neutropenia in systemic lupus erythematosus (SLE) with anti-Ro and binding of an immunologically cross-reactive neutrophil membrane antigen. Clin Exp Immunol, v. 120, p. 209-17, 2000.

16. LERNER, M. R. et al.Two novel classes of small ribonucleoproteins detected by antibodies associated with lupus erythematosus. Science, v. 21 I, p. 400, 1981.
17. Lowry, O. H. et al. Protein measurement with the folin phenol reagent. J Bio Chem, v. 193, p. 265-75, 1951.

I 8. MONIESTIER, M. Nucleolar antibodies. In:PETER,J.B.,Y.SCHOENFELD, Y. (ed.) Autoantibodies. New York: Elsevier, 1996. p. 567-73.

19. NISHIKAI, M., REICHLIN, M., Heterogeneity of precipitating antibodies in polymyositis and dermatomyosistis. Characterization of the Jo-I antibody system. Arthritis Rheum, v. 23, p. 88I-8, 1980.

20. PARODI, A. et al. Counterimmunoelectrophoresis, Elisa and immunoblotting detection of anti-Ro/SSA antibodies in subacute cutaneous lupus erythematosus. A comparative study. Br J Dermatol, v. 138, p. I|4-7, 1998.

21. PASSALEVA, A. et al. Autoantibodies to human nuclear antigens in connective tissue diseases and other disorders. Clin. Exp. Immunol, v. 63, p. 17-25, 1986.

22. POLLOCK, W.; TOH, B. H. Routine immunofluorescence detection of Ro/SS-A autoantibody using HEp-2 cells transfected with human $60 \mathrm{kDa}$ Ro/SS-A J Clin Pathol, v. 52, p. 684-7, 1999.

23. POURMAND, N. et al. Ro 52KD autoantibodies are detected in a subset of ANA-negative sera. Scand. J. Rheumatol, v. 29, p. I16-23, 2000

24. ROBBINS, W. C. et al. Complement fixation with cell nuclei and DNA in lupus erythematosus. Proc Soc Exp Biol Med, v. 96, p. 575-9, 1957.

25. ROITT, I.; BROSTOFF, J.; MALE, D. Auto-imunidade e doenças auto-imunes: o espectro das doenças auto-imunes. In: ROITT, I.M. Imunologia. 4. ed. São Paulo: Manole, 1997, v. 27, cap. 27, p. 27.I-27.13

26. SILVA, N. P. et al. Development of an enzyme-linked immunosorbent assay (Elisa) for detection of anti-native DNA antibodies using DNA from Critidia luciliae as substrate. Rev Bras Rheumatol, v. 35, n. 4, p. I83-8, 1995.

27. TAN, E. M. ; KUNKEL, H. G. Characteristics of a soluble nuclear antigen precipitating with sera of patients with with systemic lupus erythematosus. I Immunol, v. 96, p. 464-7I, 1996.

28.TAN, E. M.Antinuclear antibodies: diagnostic marker for autoimmune diseases and probes for cell biology. Adv Immunol, v. 44, p. 93, 1989.

29. WONG, K. H. et al. Measurement of anti-dsDNA: a comparative study of two Elisa and the Critidia luciliae. Pathol, v. 30, p. 57-61, 1998

Endereço para correspondência

Rita de Cassia Siqueira Bruder

Departamento de Patologia

Distrito de Rubião Ir/sn - Botucatu-SP

Tel.: (14) 3811-6238

Fax: (14) 3815-2348

e-mail: bruder28@bol.com.br 